九州大学学術情報リポジトリ

Kyushu University Institutional Repository

Larvae of the Weevil Family Curculionidae of Japan Part 4. Ceutorhynchinae to Molytinae (Insecta:Coleoptera)

Lee, Chang-Young

Entomological Laboratory, Faculty of Agriculture, Kyushu University

Morimoto, Katsura

Entomological Laboratory, Faculty of Agriculture, Kyushu University

https://doi.org/10.5109/24116

出版情報: 九州大学大学院農学研究院紀要. 40 (3/4)，pp.307-331，1996-03. Kyushu University バージョン：

権利関係 : 


\title{
Larvae of the Weevil Family Curculionidae of Japan Part 4. Ceutorhynchinae to Molytinae (Insecta:Coleoptera) ${ }^{1)}$
}

\author{
Chang-Young Lee $^{2)}$ and Katsura Morimoto \\ Entomological Laboratory, Faculty of Agriculture, \\ Kyushu University, Fukuoka 812-81, Japan \\ (Received October 26, 1995)
}

\begin{abstract}
Fourth part of the larval study on the Curculionidae deals with 18 species of the subfamilies Ceutorhynchinae, Pissodinae, Acicnemidinae, and Molytinae (=Hylobiinae). Genera treated are Rhinoncus, Mecysmodews, Homorosoma, Ceuthorrhynchidius, Ceutorhynchus, Hypurus, Pissodes, Acicnemis, Aclees, Dyscerus, and Niphades.
\end{abstract}

Subfamily Ceutorhychinae

Ceuthorrhynchinae: Emden, 1952, Proc. Zool. Soc. London, 122: 653.

Rhinoncus sp. (sibiricus Faust?)

(Fig. 1)

Body slender, moderately curved, setae minute.

Head free, dark brown, slightly longer than wide. Anterior ocellus present. Antenna not prominent, watch-glass shaped, slightly and evenly convex. Catapophyses in same plane as frons. Hypopharyngeal bracon readily discernible. Frontal suture distinguishable throughout its length, incomplete anteriorly. Endocarina absent. Frons with one pairs of seta. Dorsal epicranial setae 1 and 3 long, subequal, 2 moderately long, 4 and 5 absent. Lateral epicranial seta 1 moderately long, 2 long. Ventral epicranial setae short to moderately long, subequal. Four minute posterior epicranial setae present. Clypeal setae 1 and 2 short, subequal. Anterior margin of labrum trilobed. Labral seta 1 and 3 short, subequal, 2 long, with three setae on straight line. Median sensilla present on labrum, lateral sensilla absent. Labral rods moderately elongate, subparallel. Epipharynx with three anterolateral and six anteromedian setae and four median spines. Epipharyngeal sensory pores in two clusters, three in each cluster, postero-interior to anterior spines. Epipharynx without asperities. Mandible with two apical teeth, slightly longer than wide. Mandibular seta 1 short, slightly longer than and directly behind 2 . Labial palpus with two segments, apical segment longer than wide. Premental sclerite complete, with anterior and posterior median extensions. Postmenturn with three pairs of setae, posterior pair separated by a distance approximately one-half as great as that between setae of middle pair. Maxillary palpus with two segments, basal segment without accessory process, with one very short lateral seta, apical segment without lateral seta,

1) Contribution from the Entomological Laboratory, Faculty of Agriculture, Kyushu University, Fukuoka (Ser. 4, No.106).

2) Present address: Department of Forest Resources Protection, College of Forestry, Kangweon National University, Chuncheon 200-701, Korea. 


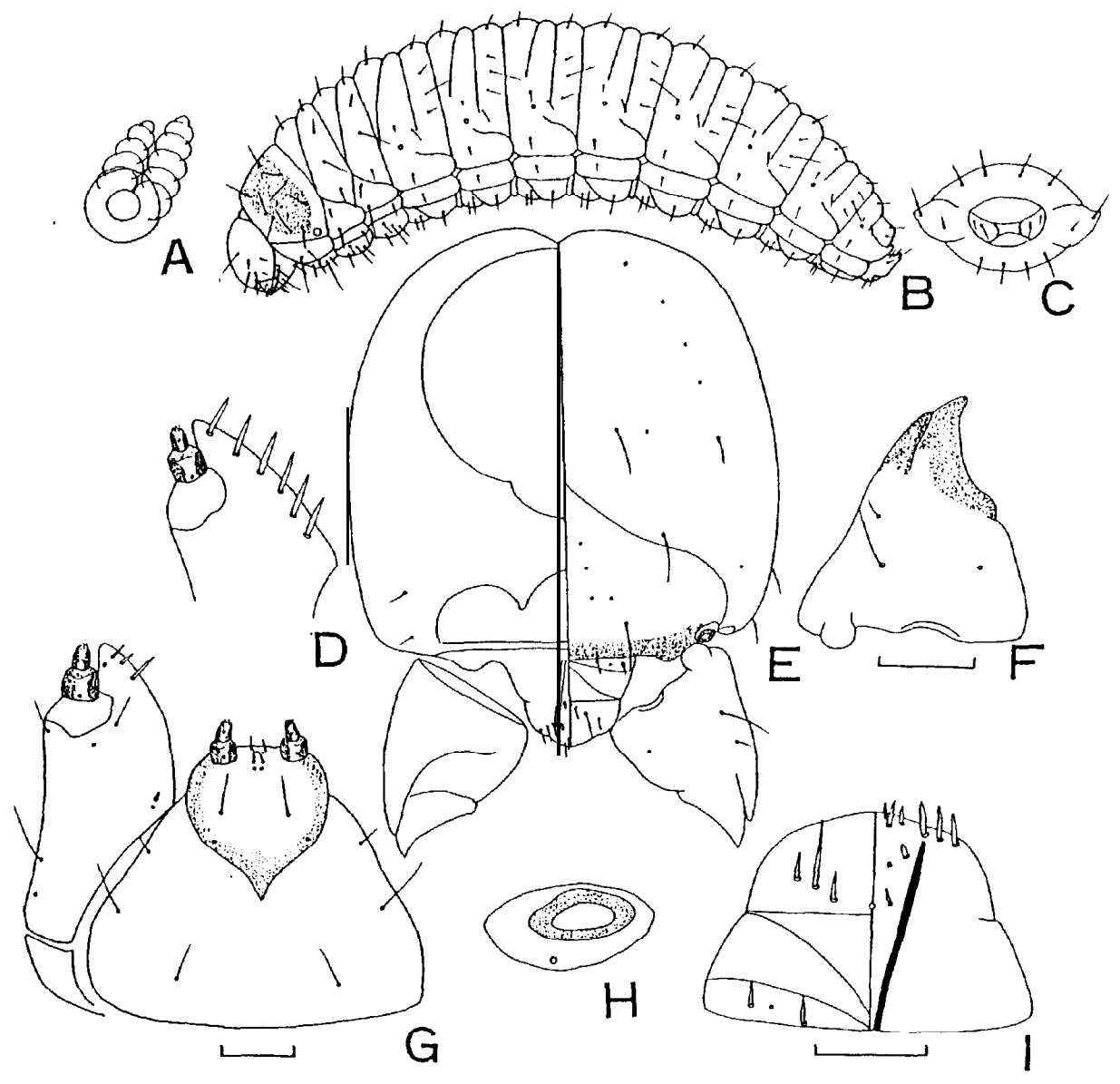

Fig. 1. Rhinoncus sp.

A: Spiracle. B: Mature larva. C: Anus. D: Maxilla, dorsal. E: Head. F: Mandible.

G: Maxilla and labium. H: Antenna. I: Labrum and epipharynx. Scale: $0.05 \mathrm{~mm}$.

apical segment longer than wide. Mala with three ventral and six dorsal setae.

Pronotum with nine setae. Thoracic spiracle bicameral. Prodorsum of meso- and metathorax with one short seta. Postdorsum of meso- and metathorax with three setae, setae 1 and 2 short, subequal, 3 moderately long. Alar area with one short seta. Spiracular area with one short seta. Epipleurum with one seta. Pleurum of prothorax with two setae, of meso-and metathorax with one seta. Pedal area with four setae, one moderately long, the remainder shorter and sternal setae. Sternal setae to setae. 
Abdomen with eight pairs of spiracles. Spiracles all lateral, bicameral, eight abdominal spiracle normal in position, not on protuberance. Typical abdominal segments with three dorsal folds. Prodorsum with one short seta. Postdorsum with four setae, setae 1, 2 and 4 short, subequal, 3 long. Spiracular area with two setae, setae 1 and 2 moderately short. Epipleurum with one short seta. Pleurum with one short seta. Pedal area with one short seta. Eusternum with two very short setae. Sternellum present. Epipleurum of eighth and ninth segments protuberant dorsally. Anus terminal, with four lobes.

Width of head $0.4 \mathrm{~mm}$.

Materials examined. Jinzenji, Kochi City, 3. ix. 1954, from stem of Polygonus blumei.

Genus Mecysmoderes Schoenherr

Mecymoderes: Gardner, 1934, Ind. For. Rec., 20: 10 (M.stylicornis).

\section{Mecysmoderes fulvus Roelofs}

(Fig. 2)

Body moderately stout, flattened ventrally, strongly convex dorsally, narrowed posteriorly, setae minute.

Head free, dark brown, slightly wider than long. Anterior ocellus present. Antenna not prominent, slightly and evenly convex, watch-glass shaped. Catapophyses in same plane as frons. Hypopharyngeal bracon readily discernible. Frontal suture distinguishable throughout its length, incomplete anteriorly. Endocarina absent. Frons with one pair of setae. Dorsal epicranial setae 1, 2, 3 and 5 long, subequal, 4 absent. Lateral epicranial seta 1 moderately long, 2 long. Ventral epicranial setae short to moderately long, subequal. Four minute posterior epicranial setae present. Clypeal setae 1 and 2 short, subequal. Anterior margin of labrum trilobed. Labral setae 1 and 3 short, subequal, 2 long, three setae in an oblique straight line. Median sensilla present on labrum, lateral sensilla absent. Labral rods moderately elongate, subparallel. Epipharynx with three anterolateral setae, six anteromedian setae and four median spines. Epipharyngeal sensory pores indistinct. Mandible with two apical teeth, longer than wide. Mandibular seta 1 short, slightly longer than and directly behind 2. Labial palpus with two segments, basal and apical segments longer than wide. Premental sclerite complete, with posterior median short extension. Postmentum with three pairs of setae, posterior pair separated by a distance approximately one-third as great as that between setae of middle pair. Maxillary palpi with two segments, basal segment without accessory process and with one very short lateral seta, apical segment without lateral seta, apical segment longer than wide. Mala with three ventral and seven dorsal setae.

Pronotum with nine setae. Thoracic spiracle bicameral. Dorsal air-tube half as long as ventral air-tube. Prodorsum of meso- and metathorax with one short seta. Postdorsum of meso- and metathorax with two setae, 1 short, 2 moderately long. Alar area with one short seta. Spiracular area with one minute seta. Epipleurum with one seta. Pleurum of prothorax with two setae, of meso- and metathorax with a moderately 


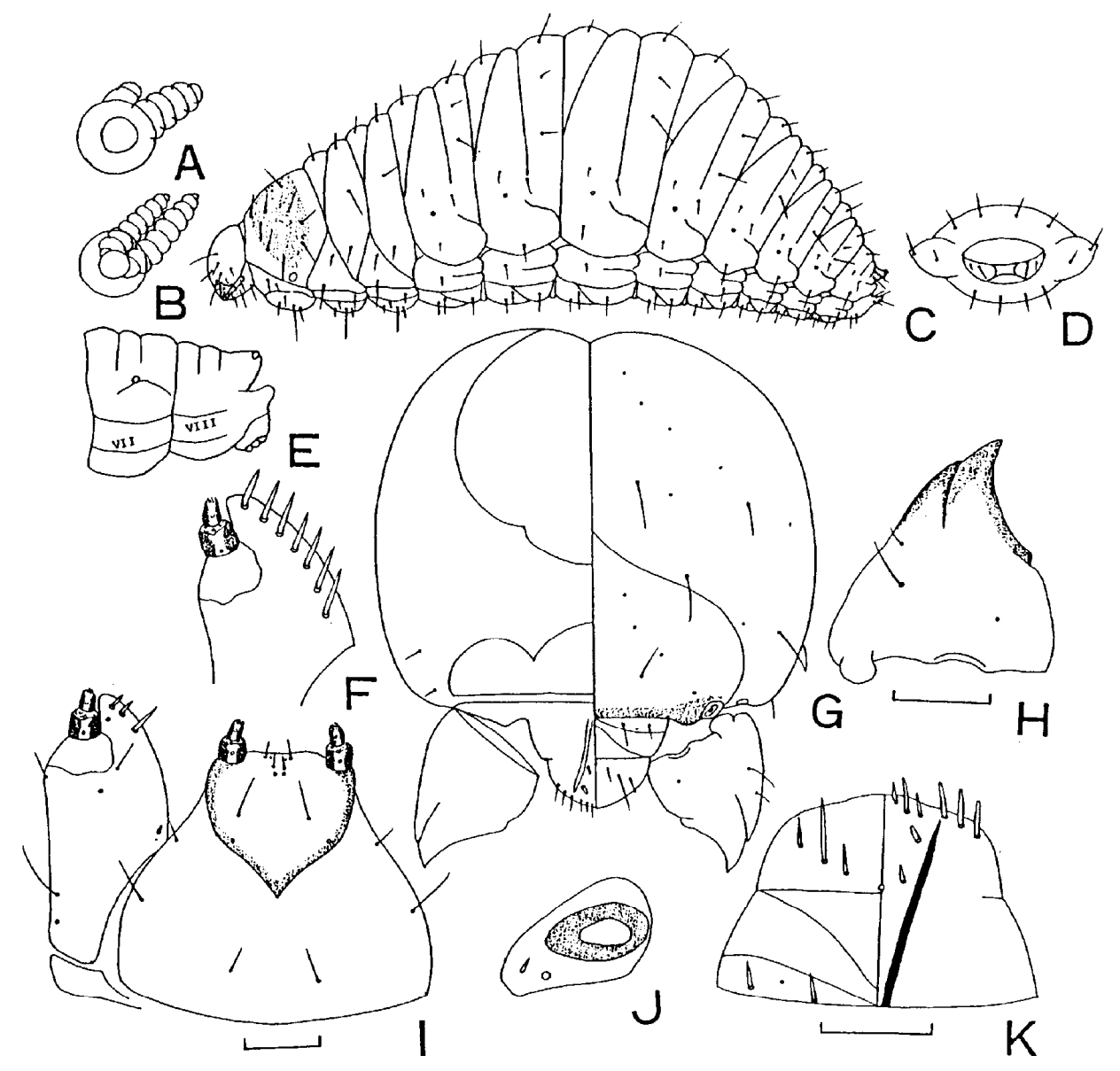

Fig. 2. Mecysmoderes fulvus Roelofs

A: Thoracic spiracle. B: Abdominal spiracle. C: Mature larva. D: Anus. E: Caudal extremity, lateral view. F: Maxilla, dorsal. G: Head. H: Mandible. I: Maxilla and labium. J: Antenna. K: Labrum and epipharynx. Scale: $0.05 \mathrm{~mm}$.

long seta. Pedal area with four setae, one moderately long, the remainder shorter and subequal to short sternal seta. Sternal setae subequal to eusternal setae.

Abdomen with eight pairs of spiracles. Spiracles all lateral, bicameral, air-tubes greatly different in size, dorsal air-tube about half as long as ventral tube on first seven segments of abdomen, eight abdominal spiracles with dorsal air-tube a little shorter than ventral air-tube. Typical abdominal segments with three dorsal folds. Prodorsum with one short seta. Postdorsum with three setae, setae 1 and 3 long, subequal, 2 short. Spiracular area with two setae, moderately short, subequal. Epipleurum with one short 
seta. Pleurum with one short seta. Pedal area with one short seta. Eusternum with two very short setae. Sternellum present. Eighth segment with a pair of papillae and spiracles located on them. Anus terminal, with four lobes.

Width of head. $0.48 \mathrm{~mm}$.

Materials examined. Mt. Hikosan, Fukuoka Pref., 16 vi.1978, from flower-buds of Rhododendron spp.

\section{Homorosoma asperum (Roelofs)}

(Fig. 3)

Body more slender, moderately curved, setae minute.

Head free, dark brown, slightly wider than long. Anterior ocellus present. Antenna not prominent, watch-glass shaped, slightly and evenly convex. Catapophyses in same plane as frons. Hypopharyngeal bracon readily discernible. Frontal suture distinguishable throughout its length, incomplete anteriorly. Endocarina absent. Frons with one pairs of setae. Dorsal epicranial setae 1, 3 and 5 long, subequal, 2 moderately long, 4 absent. Lateral epicranial setae 1 moderately long, 2 long. Ventral epicranial setae short to moderately long, subequal. Four minute posterior epicranial setae present. Clypeal setae moderately long, subequal. Anterior margin of labrum trilobed. Labral setae 1 and 3 short, subequal, 2 long, three setae in a straight line. Median sensilla present on labrum, lateral sensilla absent. Labral rods moderately elongate, subparallel. Epipharynx with three anterolateral setae, six anteromedian setae and four median spines. Epipharyngeal sensory pores in two clusters, three in each cluster, postero-median to anterior spines. Mandible with two apical teeth. Mandibular seta 1 short, slightly longer than and directly behind 2. Labial palpus with two segments, basal segment wider than long, apical segment longer than wide. Premental sclerite complete, with short posterior median extension. Postmentum with three pairs of setae, posterior pair separated by a distance approximately one-half as great as that between setae of middle pair. Maxillary palpus with two segments, basal segment without accessory process, with one very short lateral seta, the apical segment without lateral seta, basal and apical segment longer than wide. Mala with three ventral and six dorsal setae.

Pronotum with eight setae. Thoracic spiracle bicameral, air-tubes of the same size. Prodorsum of meso- and metathorax with one short seta. Postdorsum of meso- and metathorax with three setae, setae 1 and 2 short, subequal, 3 long. Alar area with one short seta. Spiracular area with one seta. Epipleurum with one moderately long seta. Pleurum of prothorax with two setae, meso- and metathorax with one moderately long seta. Pedal area with four setae, one moderately long, the remainder shorter and subequal to sternal setae. Sternal setae subequal to eusternal setae.

Abdomen with eight pairs of spiracles. Spiracles all lateral, bicameral, air-tubes of the same size, eight abdominal spiracles located interior to the base of papillae. Typical abdominal segments with three dorsal folds. Prodorsum with one short seta. Postdorsum with four setae, setae 1, 2 and 4 short, subequal, 3 long. Spiracular area with two setae, moderately short, subequal. Epipleurum with one short seta. Pleurum with one short seta. Pedal area with one short seta. Pleurum with one short seta. Pedal area with one 
short seta. Eusternum with two very short setae. Sternellum present. Eighth and ninth segments with a pair of papillae. Anus terminal, with four lobes.

Width of head $0.7 \mathrm{~mm}$.

Materials examined. Mt. Hikosan, Fukuoka Pref., 14. vi. 1955, from stems of Polygonum persicaria.

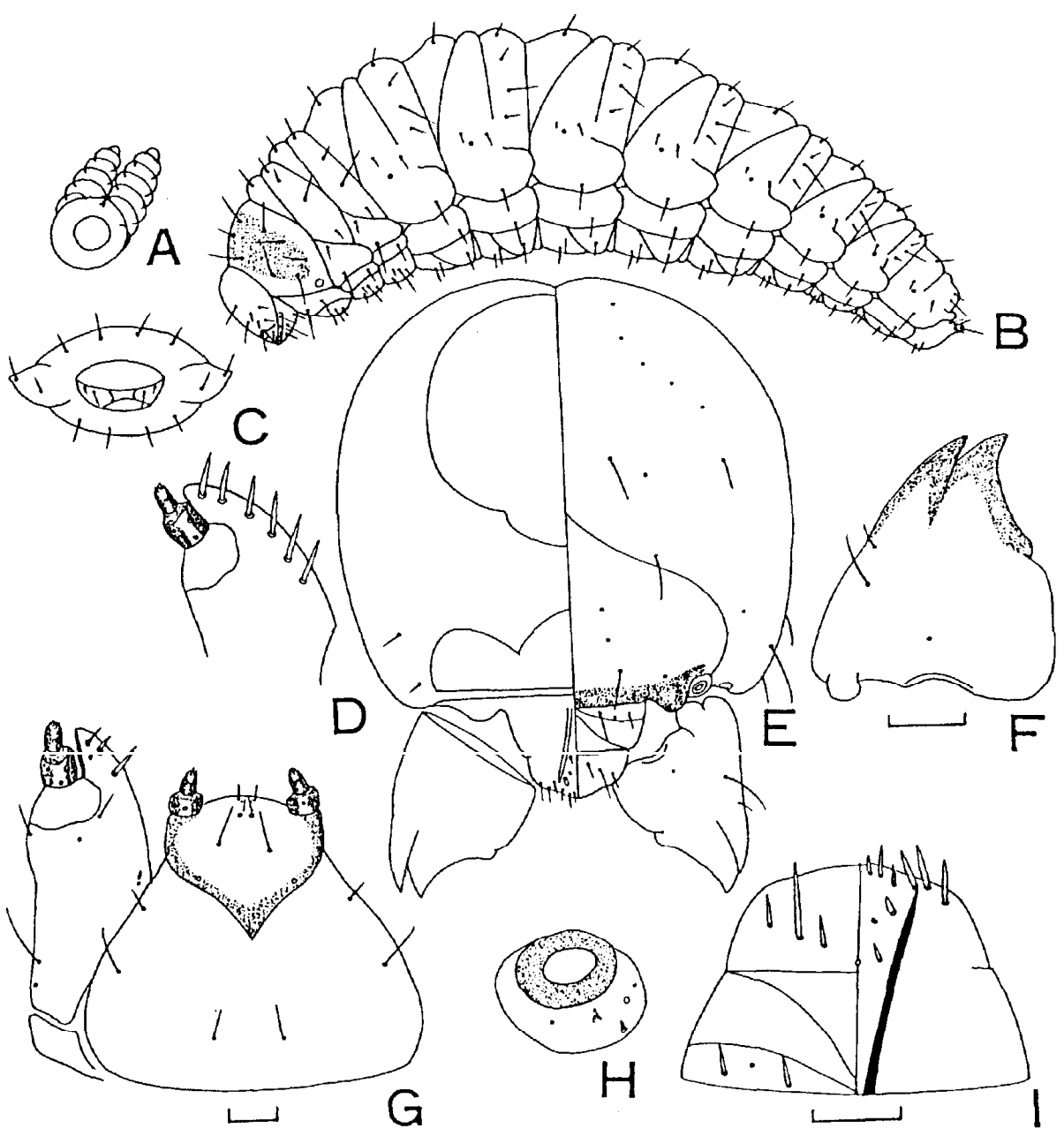

Fig. 3. Homorosoma asperum Roelofs

A: Spiracle. B: Mature larva. C: Anus. D: Maxilla, dorsal. E: Head. F: Mandible

G: Maxilla and labium. H: Antenna. I: Labrum and epipharynx. Scale: $0.05 \mathrm{~mm}$. 


\section{Ceuthorhynchidius albosuturalis (Roelofs)}

(Fig. 4)

\section{Ceuthorrhynchus albosuturalis : Morimoto, 1957, Sci. Bull. Fac. Agr., Kyushu Univ.,}

16: 64. - Hayashi, 1959,111. Ins. Larv. Jpn., :528. fig. 997.

Body moderately slender, setae minute.

Head free, dark brown, slightly wider than long. Anterior ocellus present, posterior ocellus consists of three small pigments. Antenna not prominent, evenly convex. Catapophyses in same plane as frons. Hypopharyngeal bracon readily discernible. Frontal suture distinguishable throughout its length. Endocarina absent. Frons with one pairs of seta and four pairs of sensilla. Dorsal epicranial setae 1, 3 and 5 long, subequal, 2 short, 4 absent. Lateral epicranial seta 1 moderately long, 2 long. Ventral epicranial setae short to moderately long, subequal. Four minute posterior epicranial setae present. Clypeal setae moderately short, subequal. Anterior margin of labrum trilobed. Labral setae 1 and 3 short, subequal, 2 long, three setae in an oblique straight line. Median sensilla present on labrum, lateral sensilla absent. Labral rods moderately elongate, subparallel. Epipharynx with three anterolateral setae, six anteromedian setae and four median spines. Epipharyngeal sensory pores indistinct. Mandible with two apical teeth. Mandibular seta 1 short, slightly longer than and directly behind 2. Labial palpus with two segments, apical segment longer than wide. Premental sclerite complete, posterior short median extension. Postmentum with three pairs of setae, posterior pair separated by a distance approximately one-half as great as that between setae of middle pair. Maxillary palpus with two segments, basal segment without accessory process, with one very short lateral seta and two sensilla, apical segment without lateral seta, apical segment longer than wide. Mala with three ventral and six dorsal setae.

Pronotum with ten setae. Thoracic spiracle bicameral, air-tubes of the same size, each with four constrictions, combined width much wider than peritreme. Prodorsum of meso- and metathorax with one short seta. Postdorsum of meso- and metathorax with three setae, 1 and 2 short, subequal, 3 long. Alar area with one short seta. Spiracular area with one short seta. Epipleurum with a long seta. Pleurum of prothorax with two long setae, meso-and metathorax with one long seta. Pedal area with four short setae, of which two in oval pedal lobe. Sternum with a short seta. Sternal setae subequal to eusternal setae.

Abdomen with eight pairs of spiracles. Spiracles all lateral, bicameral, of the same structure as thoracic spiracle. Typical abdominal segments with three dorsal folds. Prodorsum with one short seta. Postdorsum with one short seta. Postdorsum with four setae, 1, 2 and 4 short, subequal, 3 long. Spiracular area with two short setae. Epipleurum with one short seta. Pleurum with one short seta. Pedal area with one short seta. Eusternum with two or three very short setae. Sternellum present. Epipleurum of seventh to ninth segments more or less papillose laterally. Anus terminal, with four lobes.

Width of head. $0.4 \mathrm{~mm}$.

Materials examined. Hakozaki, Fukuoka City, 21. v. 1955, from seed-pods of Capsella bursa-postoris, Raphanus sativus, and Brassica spp.

Genus Ceutorhynchus Germar 


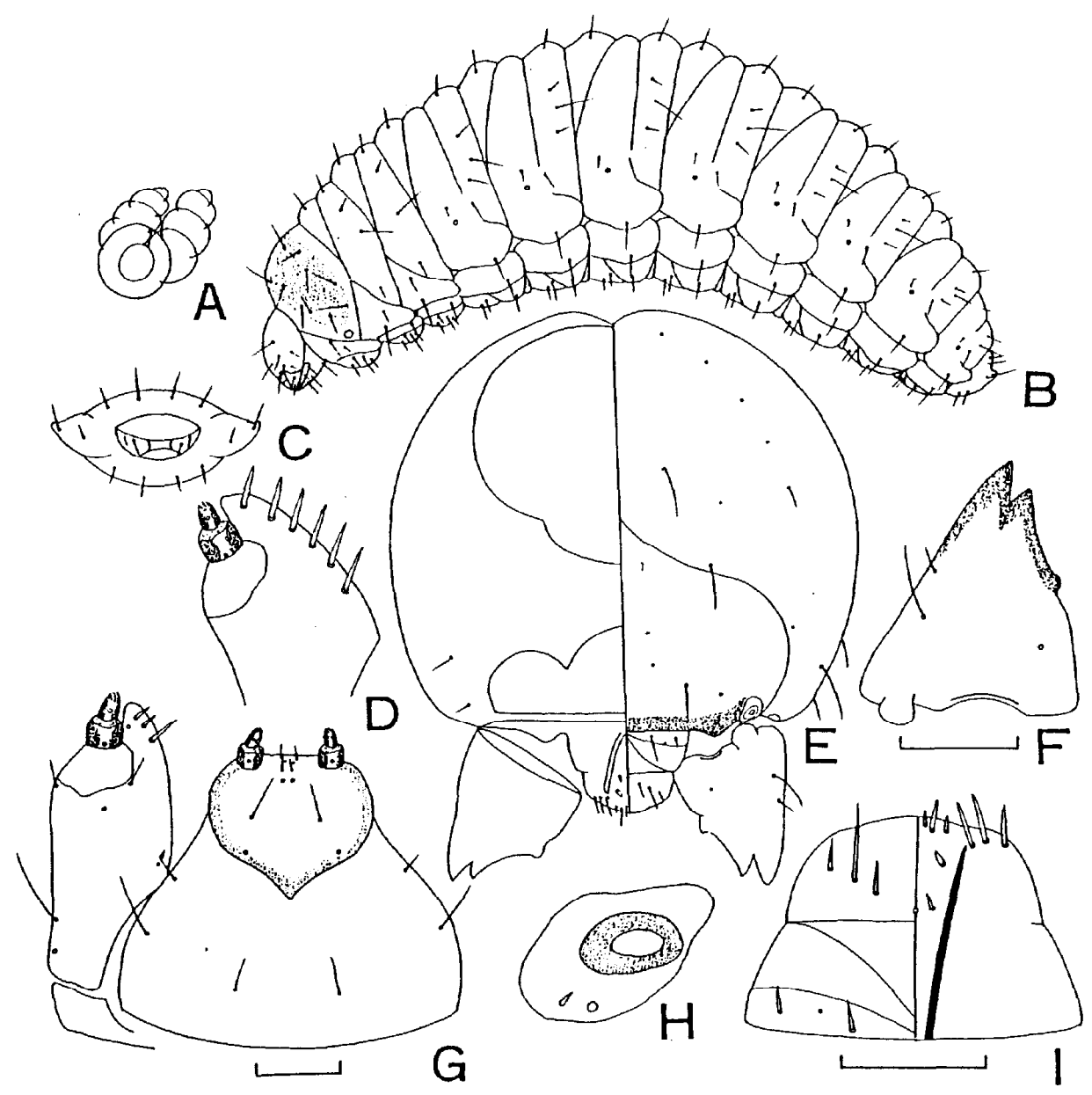

Fig. 4. Ceuthorhynchidius albosuturalis (Roelofs)

A: Spiracle. B: Mature larva. C: Anus. D: Maxilla, dorsal. E: Head. F: Mandible.

G: Maxilla and labium. H: Antenna. I: Labrum and epipharynx. Scale: $0.05 \mathrm{~mm}$.

Ceuthorhynchus : Dosse, 195.2, Zeitschr. f. angew. Ent., 34: 303 (C. napi, quadridens, \& picitarsis). - Hammad, 1957, Alexandria Journ. Agr. Res., 4: 29 (C. picitarsis). Scherf., 1964, Abh. Senckenb. naturf. Ges., 506: 320-324.

Ceutorrhynchus :Falcoz, 1926, Ann. Epiphyties, XI: 124-126 (C. sulcicollis \& quercicola). 


\section{Ceuthorhynchus rubripes Hustache}

(Fig. 5)

Body moderately stout, setae minute.

Head free, dark brown, slightly wider than long. Anterior ocellus present. Antenna not prominent, evenly convex. Catapophyses in same plane as frons. Hypopharyngeal bracon readily discernible. Frontal suture distinguishable throughout its length, incomplete anteriorly. Endocarina absent. Frons with one pairs of seta. Dorsal epicranial

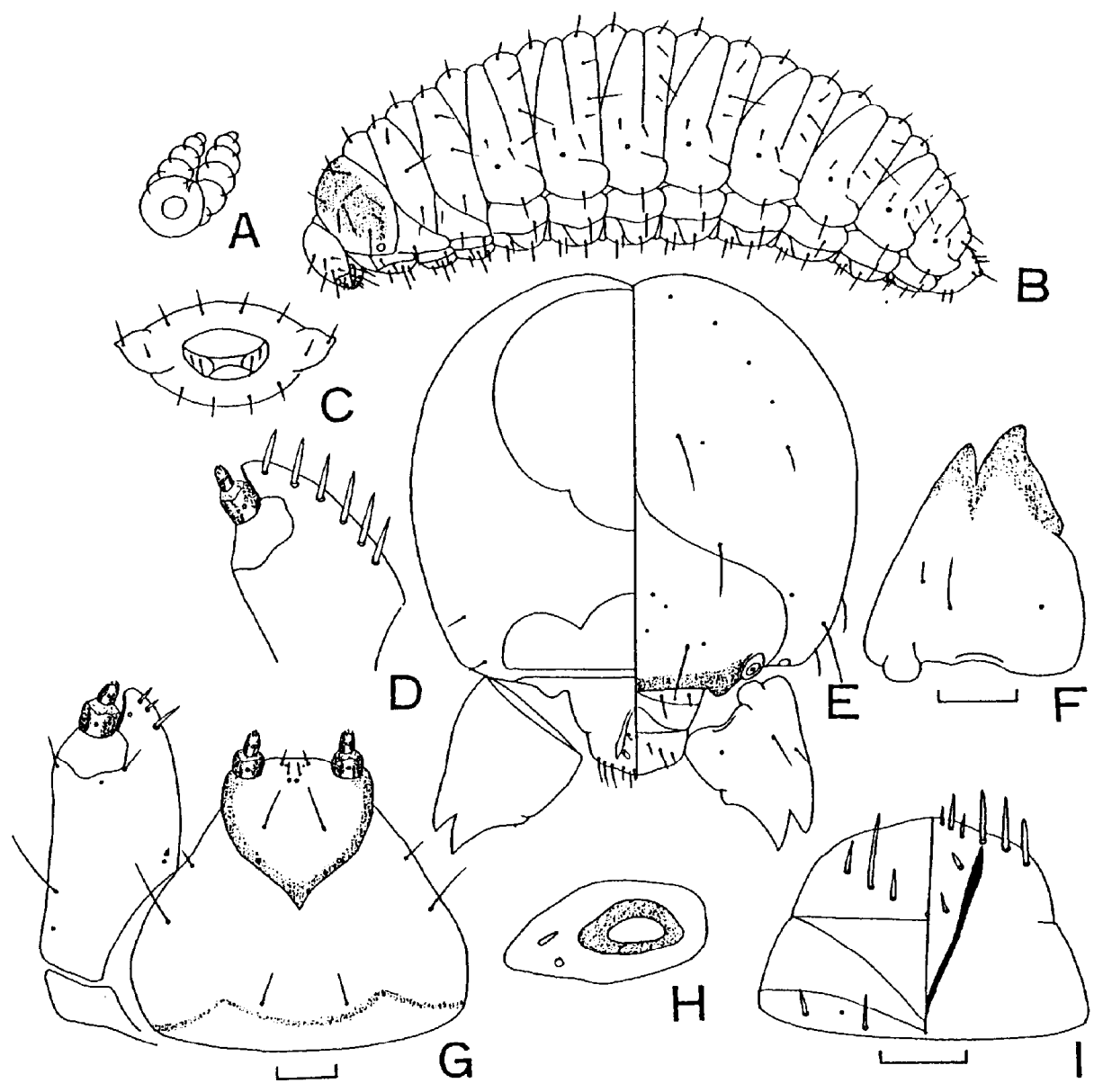

Fig. 5. Ceutorhynchus rubripes Hustache

A: Spiracle. B: Mature larva. C: Anus. D: Maxilla, dorsal. E: Head. F: Mandible G: Maxilla and labium. H: Antenna. I: Labrum and epipharynx. Scale: 0.05mm. 
setae 1, 3 and 5 long, subequal, 2 moderately long, 4 absent. Lateral epicranial seta 1 moderately long, 2 long. Ventral epicranial setae short to moderately long, subequal. Four minute posterior epicranial setae present. Clypeal setae moderately short, subeqal. Anterior margin of labrum trilobes. Labral setae 1 and 3 short, subequal, 3 long. Median sensillum present on labrum, lateral sensilla absent. Labral rods moderately elongate, subparallel. Epipharynx with three anterolateral setae, six anteromedian setae and four medial spines. Epipharyngeal sensory pores indistinct. Mandible with two apical teeth. Mandibular seta 1 short, slightly longer than and directly behind 2. Labial palpus with two segments, apical segment longer than wide. Premental sclerite complete. Postmentum with three pairs of setae, posterior pair separated by a distance approximately one -half as great as that between setae of middle pair. Maxillary palpus with two segments, basal segment without accesory process, with one very short lateral seta, apical segment without lateral seta, basal and apical segment longer than wide. Mala with three ventral and six dorsal setae.

Pronotum with nine setae. Thoracic spiracle bicameral, conjoint width of air-tubes as wide as peritreme. Prodorsum of meso- and metathorax with one short seta. Postdorsum of meso- and metathorax with three setae, setae 1 and 2 short, subequal, 3 moderately long. Alar area with one short seta. Spiracular area with a minute seta. Epipleurum with a seta. Pleurum of prothorax with two setae, of meso- and metathorax with a moderately long seta. Pedal area with four setae, one moderately long, the remainder shorter. Most ventral seta of pedal area subequal to very short sternal seta. Sternal setae subequal to eusternal setae.

Abdomen with eight pairs of spiracles. Spiracles all lateral, bicameral, similar to those of thorax. Typical abdominal segments with three dorsal folds. Prodorsum with one short seta. Postdorsum with four setae, setae 1, 2 and 4 short, subequal, 3 long. Spiracular area with two setae, setae moderately short, subequal. Epipleurum with one short seta. Pleurum with one short seta. Pedal area with one short seta. Eusternum with two very short setae. Pleurum of eighth and ninth segments not papillose. Sternellum present. Anus terminal, with four lobes.

Width of head $0.6 \mathrm{~mm}$.

Materials examined. Niigata, 15. vii. 1949, from stems of Cannabis sativa.

\section{Hypurus bertrandti (Perris)}

(Fig. 6)

Body very stout, moderately flattened ventrally, strongly convex dorsally, narrowed posteriorly.

Head retracted, dark brown, slightly wider than long. Anterior ocellus present. Antenna projecting, two to three times as wide as long, rather evenly but broadly rounded dorsally. Catapophyses in same plane as frons. Hypopharyngeal bracon readily discernible. Frontal suture distinguishable throughout its length, incomplete anteriorly. Endocarina absent. Frons with one pair of setae. Dorsal epicranial seta 5 moderately long, 1, 2, 3, and 4 absent. Lateral epicranial setae absent. Ventral epicranial setae absent, Four minute posterior epicranial setae present. Clypeal seta moderately short, 
subequal. Anterior margin of labrum trilobed. Labral setae 1 and 3 short, subequal, 2 long. Median sensillum present on labrum, lateral sensilla absent. Labral rods moderately elongate, subparallel. Epipharynx with three anterolateral setae, six anteromedian setae and four median spines, without asperities. Epipharyngeal sensory pores indistinct. Mandible with two apical teeth. Mandibular seta 1 short, slightly longer than and directly behind 2. Labial palpus with two segments, apical segments longer than wide. Premental sclerite complete. Postmenturn with three pairs of setae, posterior pair separated by a distance approximately one-half as great as that between setae of middle pair. Maxillary

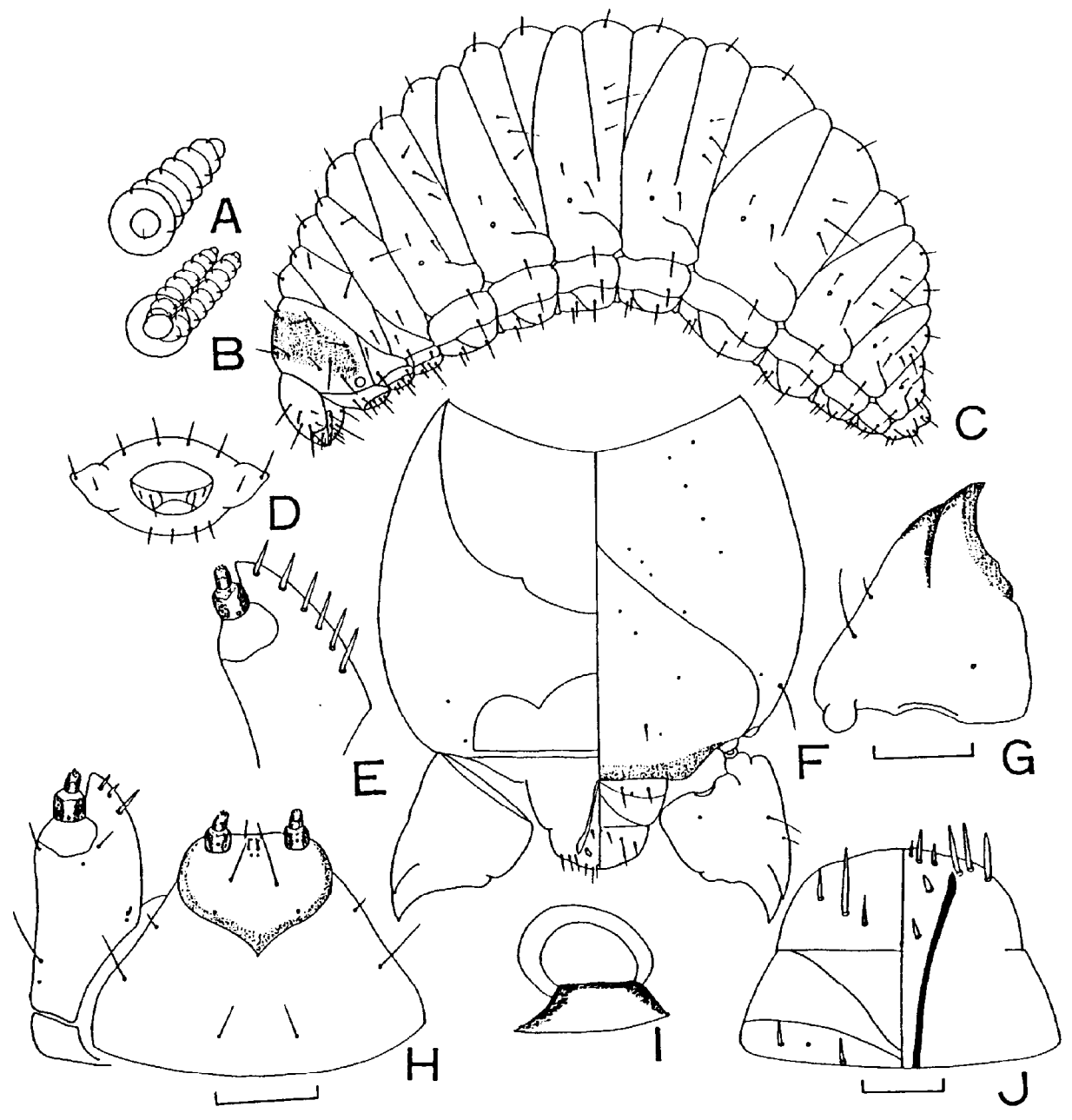

Fig. 6. Hypurus bertrandti (Perris)

A: Thoracic and 1-7th abdominal spiracle. B: 8th abdominal spiracle. C: Mature larva. D: Anus. E: Maxilla, dorsal. F: Head. G: Mandible. H: Maxilla and labium. I: Antenna. J. Labrum and epipharynx. Scale: $0.05 \mathrm{~mm}$. 
palpus with two segments, basal segment without accessory process, with one very short lateral seta, apical segment without lateral seta, apical segment longer than wide. Mala with three ventral and six dorsal setae.

Pronotum with nine setae. Thoracic spiracle unicameral. Prodorsum of meso- and metathorax with one short seta. Postdorsum of meso- and metathorax with three setae, setae 1 and 2 short, subequal, 3 long. Alar area with one short seta. Spiracular area with a seta. Epipleurum with a seta. Pleurum of prothorax with two setae, of meso- and metathorax with a seta. Pedal area with four setae, one moderately long, the remainder shorter and subequal to short sternal setae. Sternal setae subequal to eusternal setae.

Abdomen with eight pairs of spiracles. Spiracles all lateral, first to seventh spiracles unicameral, eighth spiracle bicameral. Typical abdominal segments with three dorsal folds. Prodorsum with one short seta. Postdorsum with four setae, setae 1, 2 and 4 short, subequal, 3 long. Spiracular area with two setae, setae moderately short, subequal. Epipleurum with one short seta. Pleurum with one short seta. Pedal area with one short seta. Eusternum with two very short setae. Sternellum present. Anus terminal, with four lobes.

Width of head. $0.43 \mathrm{~mm}$.

Materials examined. Hakozaki, Fukuoka City, 20. vii. 1982, leaf-miner of Portulaca oleracea.

This species is characteristic in having the unicameral spiracles on the thorax and first seven abdominal segments, and the broadly emarginate head at the posterior margin.

\section{Genus Pissodes Germar}

(Figs. 7-8)

Pissodes : Hopkins, 1911, U. S. D. A., Bur. Ent., Tech. Ser., 20: 23. - Anderson,1947, Proc.

Ent. Soc. Wash., 49: 123. - De Viedema, 1963, Eos, 39: 269.

Body moderately curved, cylindrical, with relatively coarse skin-points.

Head free, dark orange, as long as wide, broadest at middle, rounded posteriorly. Anterior ocellus present, posterior ocellus absent. Antenna with one conical segment and several minute setae. Catapophyses in same plane as frons. Hypopharyngeal bracon readily discernible. Frontal suture distinguishable thoughout its length. Epicranial suture more than one-half as long as head. Endocarina distinct, approximately one-half as long as frons. Frons with five pairs of setae, setae 1, 2 and 3 short to moderately long, subequal, 4 and 5 long, subequal. Dorsal epicranial setae 1, 3 and 5 long, subequal, 2 moderately long, 4 short. Lateral epicranial seta 1 moderately long, 2 long. Ventral epicranial setae short to moderately long, subequal. Four minute posterior epicranial setae present. Clypeal seta 1 short to moderately long, nearly twice as long as 2 . Anterior margin of labrum trilobed, with strong median extension of posterior margin into clypeal zone. Labral setae 1 and 2 short to moderately long, nearly twice as long as 3. Median and paired lateral sensilla present on labrum. Labral rods moderately stout,subparallel. Epipharynx with three anterolateral setae, six anteromedian setae and four median spines. Epipharyngeal sensory pores in two clusters, three in each cluster, between the anterior and posterior pairs of median spines. Epipharynx with or without asperities. 
Mandible with two apical teeth. Mandibular seta 1 short, slightly longer than and directly behind 2. Labial palpus with two segments, apical segment longer than wide. Premental sclerite complete, with anterior and posterior median extensions. Postmentum with three pairs of setae, posterior pair separated by a distance approximately one-half as great as that between setae of middle pair. Maxillary palpus with two segments, basal segment without accessory process, with one very short lateral seta, apical segment without lateral seta, apical segment longer than wide. Mala with five ventral and seven dorsal setae.

Pronotum with ten setae. Thoracic spiracle bicameral, with surrounding wrinkles.

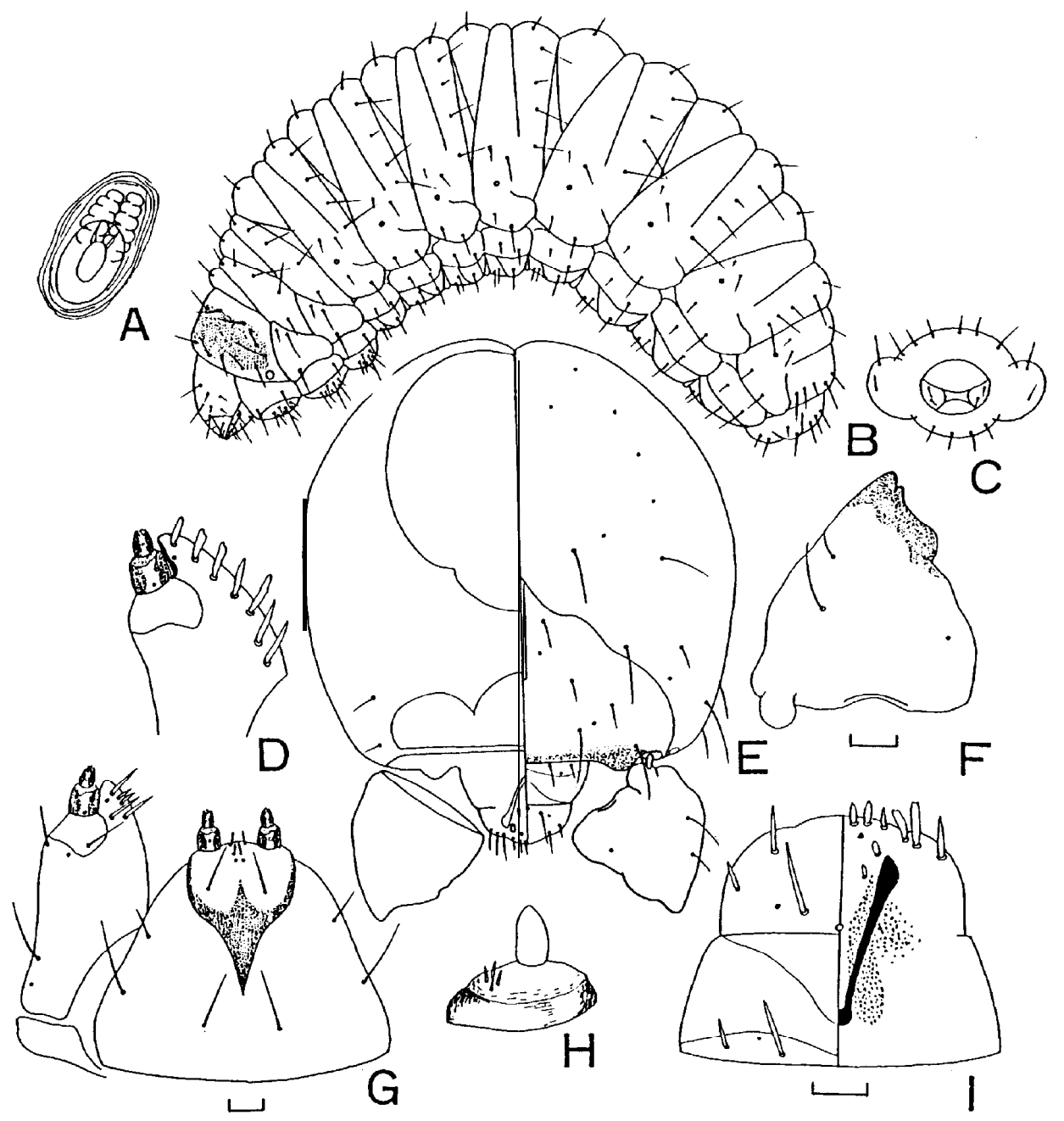

Fig. 7. Pissodes nitidus Roelofs

A: Spiracle. B: Mature larva. C: Anus. D: Maxilla, dorsal. E: Head. F: Mandible.

G: Maxilla and labium. H: Antenna. I: Labrum and epipharynx. Scale: $0.1 \mathrm{~mm}$. 


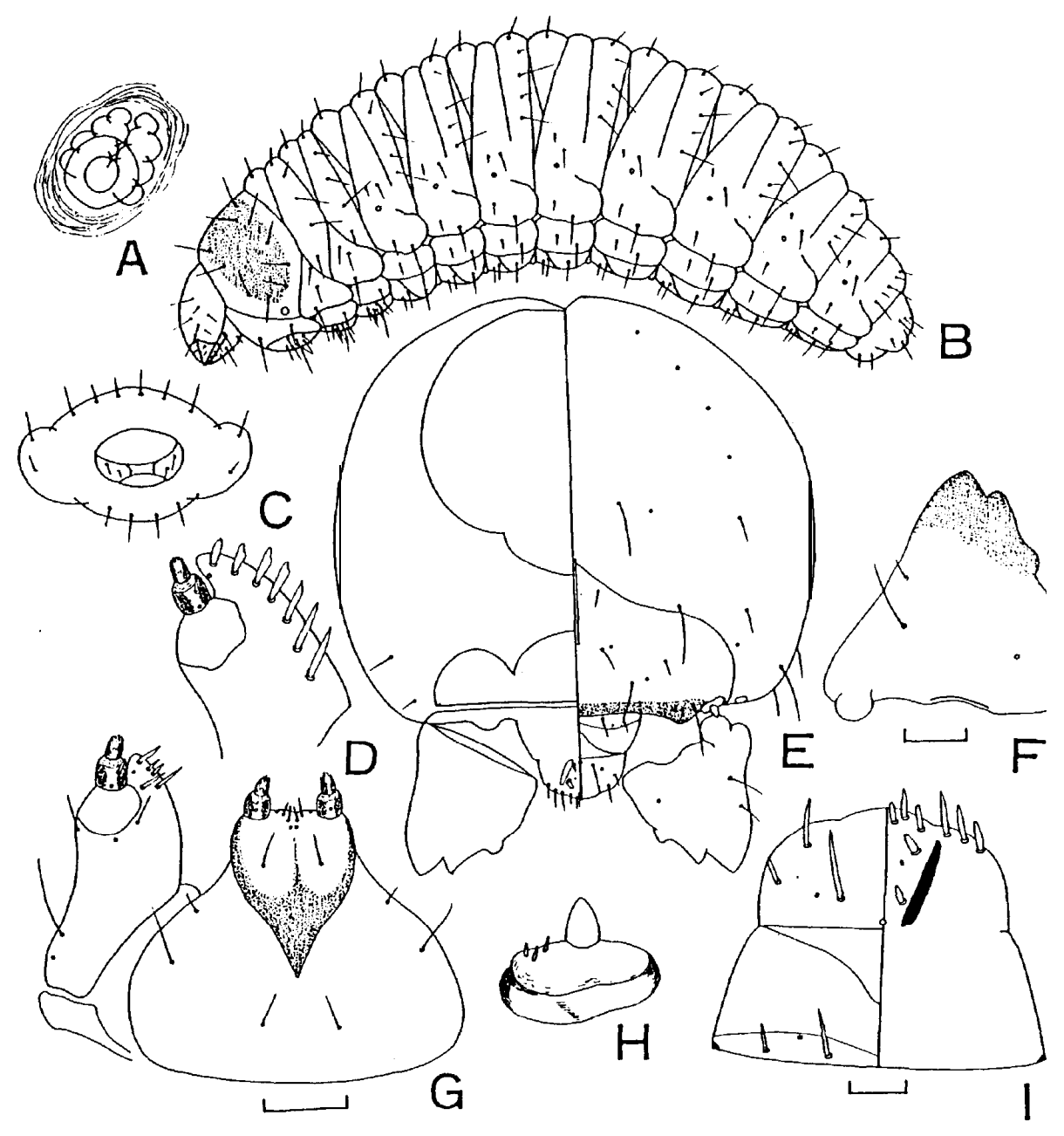

Fig. 8. Pissodes cembrae Motschulsky

A: Spiracle. B: Mature larva. C: Anus. D: Maxilla, dorsal. E: Head. F: Mandible.

G: Maxilla and labium. H: Antenna. I: Labrum and epipharynx. Scale: $0.1 \mathrm{~mm}$.

Prodorsum of meso- and metathorax with one short seta. Postdorsum of meso- and metathorax with four setae, setae 1 and 2 short, subequal, 3 and 4 moderately long, subequal. Alar area with one short seta. Spiracular area with two setae, one very short. Epipleurum with one seta. Pleurum of prothorax with two setae, of meso- and metathorax with a seta. Pedal area with seven setae, one moderately long, the remainder shorter and subequal to sternal seta. Sternal setae subequal to eusternal setae.

Abdomen with eight pairs of spiracles. Spiracles all lateral, bicameral, with surrounding wrinkles. Typical abdominal segments with three dorsal folds. Prodorsum 
with one short seta. Postdorsum with setae, 1 short, 5 long. Spiracular area with two setae, seta 1 very short, seta 2 short. Epipleurum with two setae, one short, the other slightly longer. Pleurum with two setae, one short, the other slightly longer. Pedal area with one short seta. Eusternum with two very short setae. Sternellum present. Anus terminal, with four lobes.

\section{Key to species examined}

1. Labral rods long and convergent posteriorly, epipharynx asperate.. Postdorsal setae 2 and 4 of typical abdominal segments moderately long to long ......... Pissodes nitidus

-. Labral rods subparallel, short, epipharynx not asperate. Postdorsal setae 2 and 4 of typical abdominal segments short ............................................................... 2

2. Postmentum not asperate, premental sclerite with long median anterior and posterior extensions ................................................................... Pissodes cembrae

-. Postmentum asperate at latro-posterior areas, premental sclerites with median anterior extension weak

Pissodes obscurus

Species and materials examined.

Pissodes nitidus Roelofs. Meguro, Tokyo. 24.vii.1950, under bark of Pinus spp.

Pissodes obscurus Roelofs. Kumamoto, xi. 1975. under bark of Pinus spp.

Pissodes cembrae Motschlusky. Hokkaido, 7. v. 1969, under bark of Abies sachalinensis.

\section{Genus Acicnemis Lacordaire}

(Fig. 9)

Acicnemis : Gardner, 1934, Ind. For. Rec., 20: 20.

Body moderately curved, almost cylindrical, covered for the most part with relatively coarse skin-points.

Head free, light to dark brown, with two fairly distinct longitudinal pale streaks on each side. Anterior ocellus present. Antenna normal, with short conical apical segment. Catapophyses in same plane as frons. Hypopharyngeal bracon readily discernible. Frontal suture fine, sometimes vague near posterior angle. Endocarina distinct, approximately one-half as long as frons. Frons with five pairs of setae, setae 1, 2 and 3 short, subequal, 4 and 5 long, subequal. Dorsal epicranial setae 1, 3 and 5 long, subequal, 2 moderately long, 4 short. Lateral epicranial seta 1 moderately long, 2 long. Ventral epicranial setae short to moderately long, subequal. Four minute posterior epicranial setae present. Clypeus rather wide but not longer than labrum. Clypeal seta 1 and 2 moderately long, subequal. Labrum about twice as wide as long, anterior margin almost evenly and weakly arched, posterior margin nearly straight, only very weakly extended into clypeus. Labral setae 1, 2 and 3 moderately long, subequal. Median and paired lateral sensilla present on labrum. Labral rods moderately elongate, stout, which extend about to epistoma, subparallel. Epipharynx with three anterolateral setae, six 


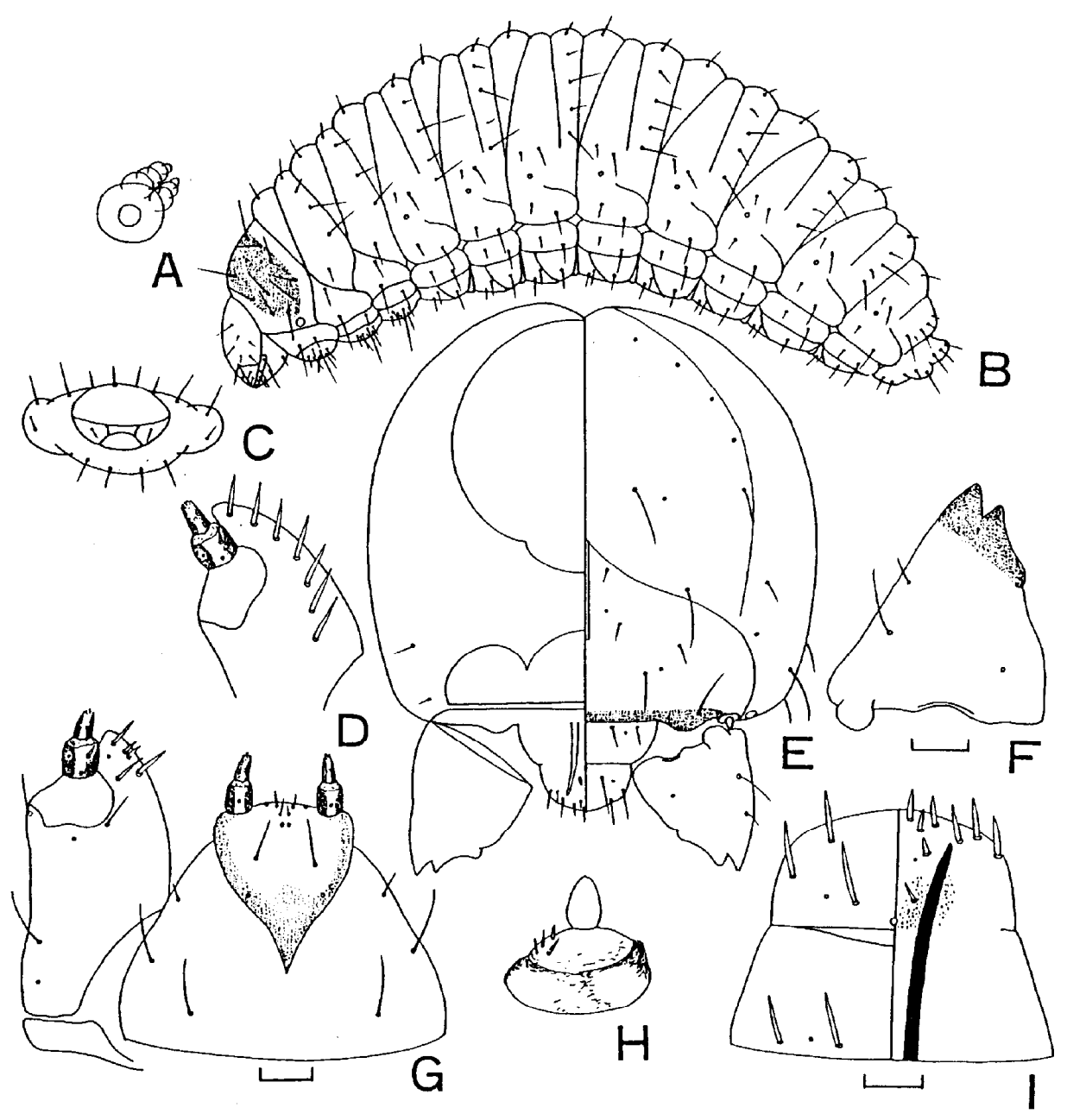

Fig. 9. Acicnemis palliata Pascoe

A: Spiracle. B: Mature larva. C: Anus. D: Maxilla, dorsal. E: Head. F: Mandible.

G: Maxilla and labium. H: Antenna. I: Labrum and epipharynx. Scale: $0.1 \mathrm{~mm}$.

anteromedian setae and four median spines. Epipharyngeal sensory pores in two clusters, three in each cluster, behind anterior spines. Epipharynx with asperities. Mandible with small angulation or tooth before the middle of cutting edge. Mandibular seta 1 short, slightly longer than and directly behind 2. Labial palpus with two segments, basal segment longer than wide, apical segment twice as long as wide. Premental sclerite complete, posteriorly acute triangle. Postmentum with three pairs of setae, posterior pair separated by a distance approximately one-half as great as that between setae of middle pair. Maxillary palpus with two segments, apical segment longer than wide. Mala with 
five ventral and seven dorsal setae.

Pronotum with ten setae. Thoracic spiracle bicameral. Prodorsum of meso- and metathorx with one short seta. Postdorsum of meso- and metathorax with four setae, setae 1 and 2 short, subequal, 3 and 4 moderately long, subequal. Alar area with one short seta. Spiracular area with a short seta. Epipleurum with a moderately long seta. Pleurum of prothorax with two setae, of meso- and metathorax with a long seta. Pedal area with seven setae, one moderately long, the remainder shorter and subequal to short sternal seta. Sternal setae subequal to eusternal setae.

Abdomen with eight pairs of spiracles. Spiracles all lateral, bicameral. Typical abdominal segments with three dorsal folds. Prodorsum with one short seta. Postdorsum with five setae, setae 1, 2 and 4 short, subequal, 3 and 5 moderately long, subequal. Spiracular area with two setae, seta 1 very short, seta 2 short. Epipleurum with two setae, one short, the other slightly long. Pleurum with two setae, one short, the other slightly longer. Pedal area with one short seta. Eusternum with two very short setae. Sternellum present. Anus terminal, with four lobes.

Key to species examined

1. Mandible with a large obtuse tooth before the middle of cutting edge, upper margin of buccal face with one or two small but distinct acute teeth

-. Mandible with an indistinct swelling before the middle of cutting edge, without tooth on buccal face Acicnemis palliata

2. Premedian tooth of mandible on cutting edge pointed apically and close to inner apical tooth, upper margin of buccal face with one acute tooth Acicnemis sp.

-. Premedian tooth of mandible on cutting edge roundly produced internally, upper margin of buccal face with two and well separated teeth Acicnemis suturalis

Species and materials examined.

Acicnemis palliata Pascoe. Mitsushimacho, Tsushima, 24. iv.1964, from dead vines of Wistaria floribunda.

Acicnemis suturalis Roelofs. Mt. Wakasugi, Fukuoka Pref., 23.v.1954, from dead vines of Wistaria brachybotrys.

Acicnemis sp.(probably luteomaculata Morimoto et Miyakawa, Mt. Aoidake, Miyazaki Pref., 22.viii.1975, in dead stem of Shiia sieboldii.

Subfamily Molytinae (=Hylobiinae)

(Figs. 10-13)

Hylobiinae: Gardner, 1934, Ind. For. Rec., 20: 24. - Gardner, 1938, Ind. For. Res., Ent., 3: 233.

Genus Aclees Schoenherr

Aclees : Gardner, 1938, Ind. For. Rec., Ent., 3: 234 (A. birmanicus). 


\section{Aclees hirayamai Kôno}

(Fig. 10)

Body nearly cylindrical, moderately stout, tergal area from metanotum to seventh segment of abdomen with coarse brown asperities.

Head free, brown, with a short pale longitudinal streak on each side of epicranial suture, as long as wide. Anterior ocellus present. Antenna with a conical segment and several minute setae. Catapophyses in same plane as frons. Hypopharyngeal bracon readily discernible. Frontal suture distinguishable throughout its length, incomplete anteriorly. Endocarina distinct, approximately one-half as long as frons. Frons with five pairs of setae, setae 1, 2 and 3 short to moderately long, subequal, 4 and 5 long, subequal. Dorsal epicranial setae 1, 3 and 5 long, subequal, 2 moderately long, 4 short. Lateral epicranial seta 1 moderately long, 2 long. Ventral epicranial seta short to moderately long, subequal. Four minute posterior epicranial setae present. Clypeus with angular sides and straight anterior edge, clypeal setae moderately long, subequal. Anterior margin of labrum weakly trilobed, posterior margin strongly produced into clypeal zone, labrum less than twice as wide as long. Median and a pair of lateral sensilla present on labrum. Labral seta 3 as long as 2, below seta 1. Labral rods moderately straight and short, stout. Epipharynx with hair-like dense asperities between rods, with three anterolateral setae, six anteromedian setae and four median spines. Epipharyngeal sensory pores in two clusters, three in each cluster, near the inner base of anterior spines. Mandible with two apical teeth, and an obtuse tooth in the middle of cutting edge. Labial palpus with two segments, basal and apical segment longer than wide. Premental sclerite complete, forming an elongate posteriorly acute triangle. Postmentum with three pairs of setae, posterior pair separated by a distance approximately one-half as great as that between setae of middle pair. Maxillary palpus with two segments, basal segment without accessory process, with one very short lateral seta, apical segment without lateral seta. Mala with five ventral and seven dorsal setae, asperate below dorsal setae.

Pronotum with ten setae. Thoracic spiracle bicameral, strongly transverse, twice or more as long as wide, peritreme longer than air-tubes, spiracle surrounded by a fine oval ridge. Prodorsum of meso- and metathorax with one short seta. Postdorsum of mesoand metathorax with four setae, setae 1 and 2 short, subequal, 3 and 4 moderately long, subequal. Alar area with one short seta. Spiracular area with one minute and one moderately long setae. Epipleurum with a long seta. Pleurum of prothorax with two setae, of meso- and metathorax with one seta. Pedal area with seven setae, one moderately long, the remainder shorter and subequal to short sternal seta. Sternal setae subequal to eusternal setae.

Abdomen with eight pairs of spiracles. Spiracles all lateral, bicameral, same as those of thorax. Typical abdominal segments with three dorsal folds. Prodorsum with one short seta. Postdorsum with five setae, setae 1, 2 and 4 short, subequal, 3 and 5 long, subequal. Spiracular area with two setae, one very short, seta 2 short. Epipleurum with two setae, one short, the other slightly longer. Pleurum with two setae, one short, the other slightly longer. Pedal area with one short seta. Eusternum with two very short setae. Sternellum present. Anus terminal, with four lobes.

Width of head $4.1 \mathrm{~mm}$. 


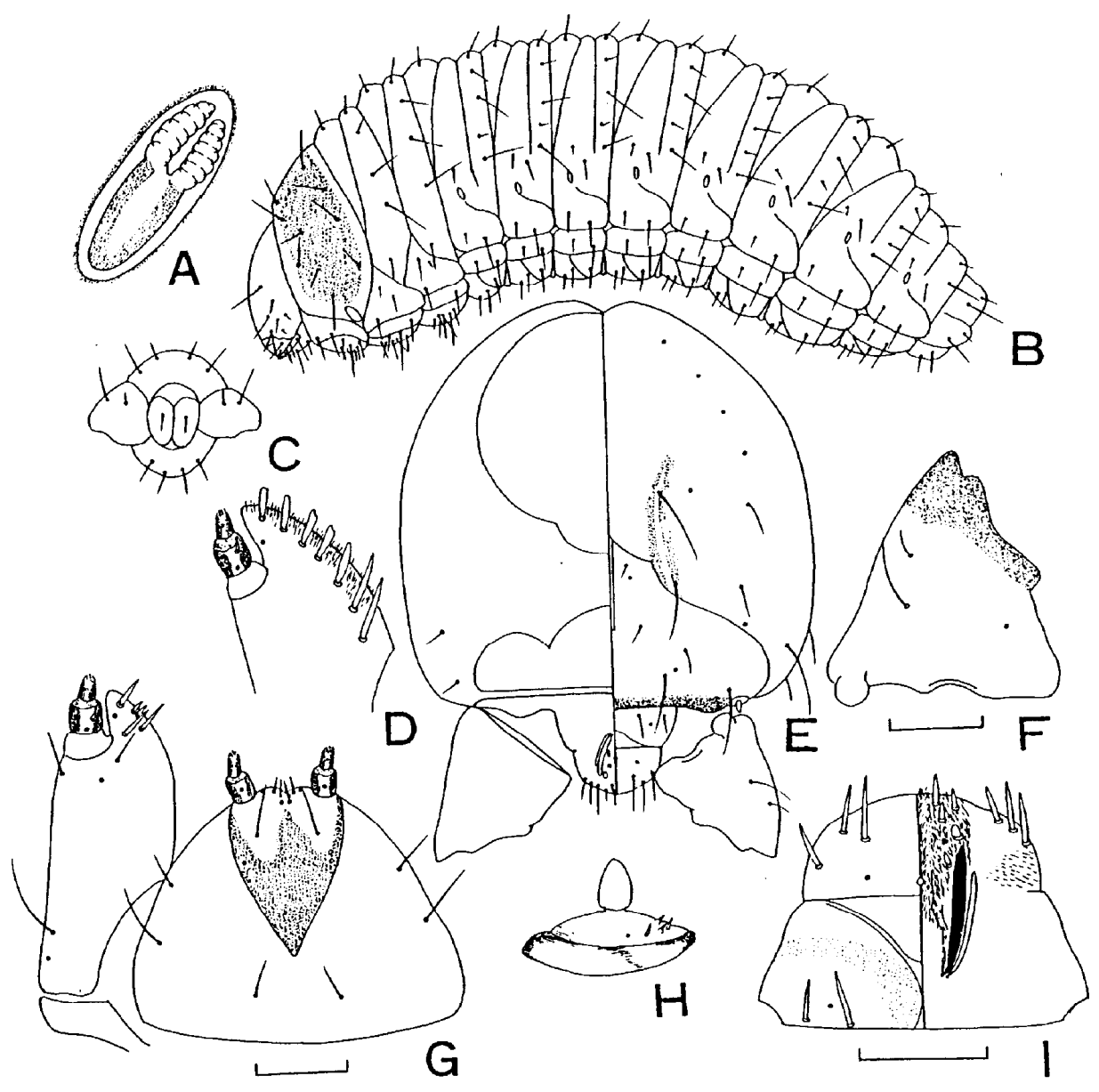

Fig. 10. Aclees hirayamai Kôno

A: Spiracie. B: Mature larva. C: Anus. D: Maxilla, dorsal. E: Head. F: Mandible.

G: Maxilla and labium. H: Antenna. I: Labrum and epipharynx. Scale: 0.5mm.

Materials examined. Hachijo I., 2. vi. 1981, from Ficus elastica in a glass-house.

\section{Genus Dyscerus Faust}

(Figs. 11-12)

Hylobius desbrochersi : Chûjô \& Morimoto, 1956, Shinrin-boeki news, 5(10): 240. (= D. perforatus). 
Body nearly cylindrical, very stout, skin with minute asperities.

Head free, dark brownish, with a short pale longitudinal streak on each side of epicranial suture. Anterior ocellus present. Antenna with a conical accessory sensory appendage and several minute setae. Catapophyses in same plane as frons. Hypopharyngeal bracon readily discernible. Frontal suture distinguishable thoughout its length. Endocarina distinct, approximately one-half as long as frons. Frons strongly transverse, with five pairs of setae, setae 1,2 and 3 short to moderately long, subequal, 4 and 5 long, subequal. Dorsal epicranial setae 1, 3 and 5 long, subequal, 2 moderately long,

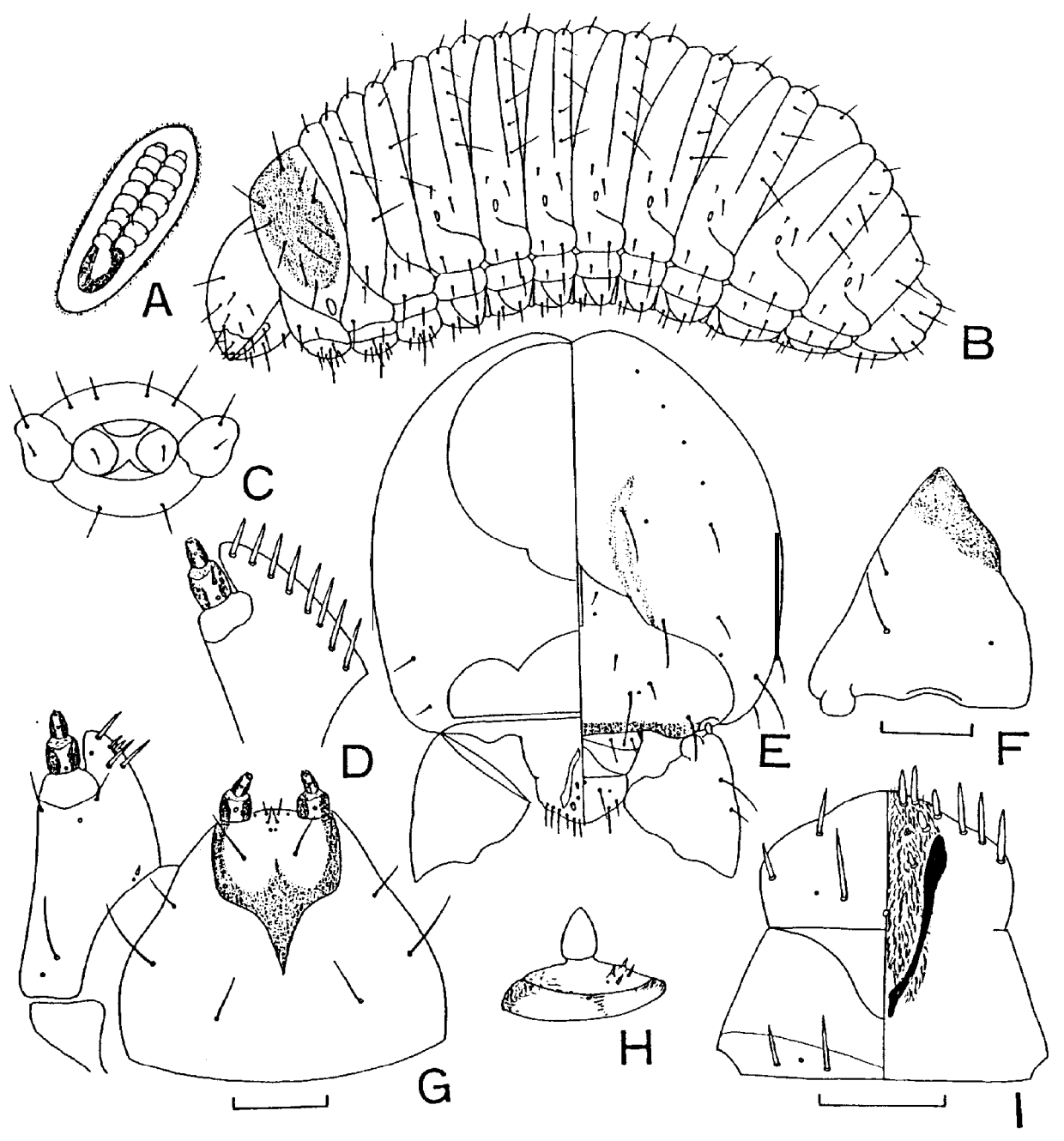

Fig. 11. Dyscerus exsculptus (Roelofs)

A: Spiracle. B: Mature larva. C: Anus. D: Maxilla, dorsal. E: Head. F: Mandible.

G: Maxilla and labium. H: Antenna. I: Labrum and epipharynx. Scale: $0.5 \mathrm{~mm}$. 


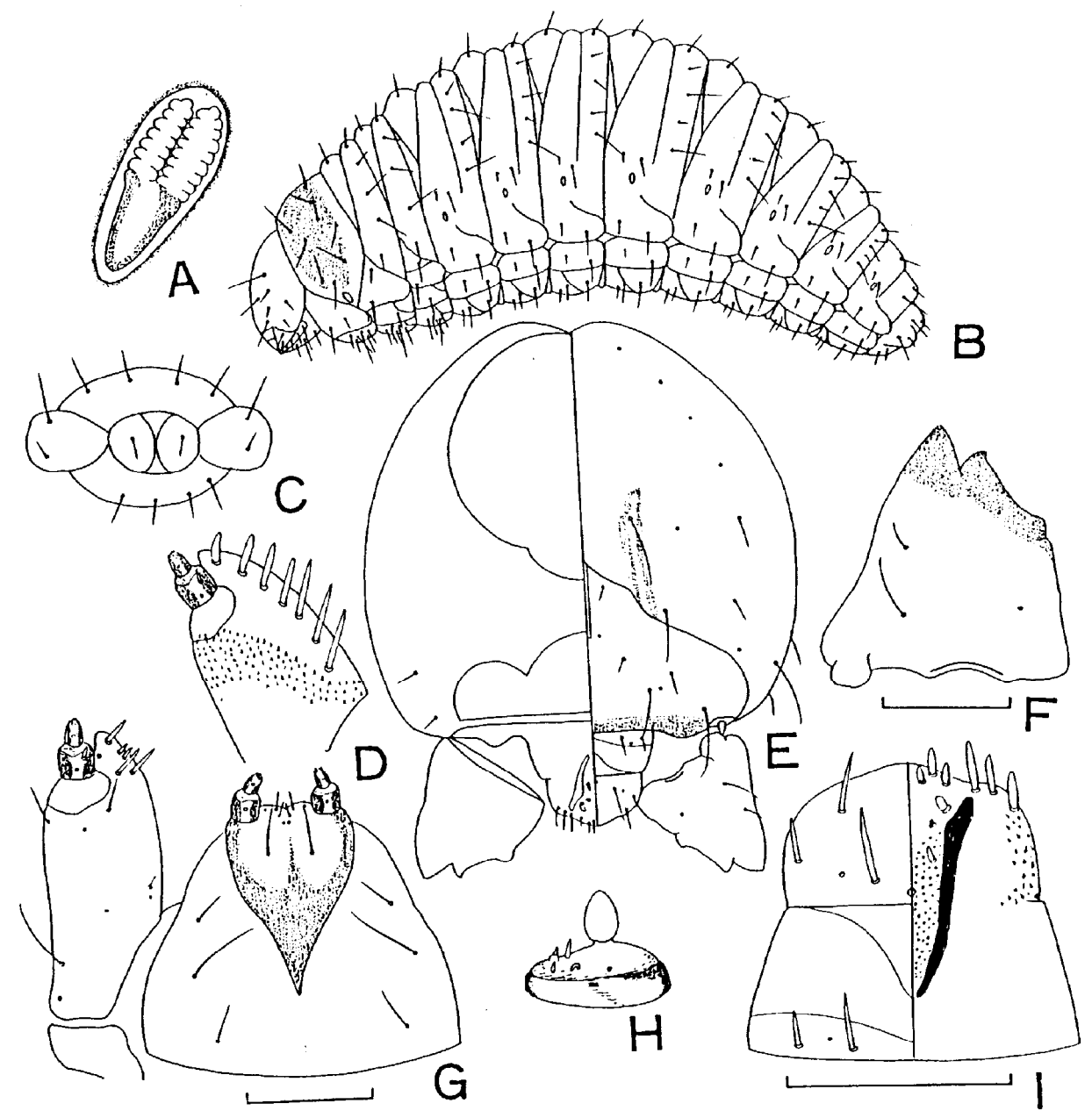

Fig. 12. Dyscerusorientalis (Motschulsky)

A: Spiracle. B: Mature larva. C: Anus. D: Maxilla, dorsal. E: Head. F: Mandible. G: Maxilla and labium. H: Antenna. I: Labrum and epipharynx. Scale: $0.5 \mathrm{~mm}$.

4 short. Lateral epicranial seta 1 moderately long, 2 long. Ventral epicranial setae short to moderately long, subequal. Four minute posterior epicranial setae present. Clypeal seta 1 short to moderately long, nearly twice as long as 2 . Labrum about twice as wide as long. Anterior margin of labrum trilobed, posterior margin strongly produced into clypeal zone. Labral setae 1 and 2 short to moderately long, nearly twice as long as 3. Median and paired lateral sensilla present on labrum. Labral rods moderately straight, and slightly convergent. Epipharynx with hair-like asperities between rods, with three anterolateral setae, six anteromedian setae and four median spines. Epipharyngeal 
sensory pores in two clusters, near inner base of antaerior spines. Mandible with one or two apical teeth. Mandibular seta 1 short, slightly longer than and directly behind 2 . Labial palpus with two segments, basal segment wider than long or longer than wide, apical segment longer than wide. Premental sclerite complete, with median anterior and posterior extensions. Postmentum with three pairs of setae, posterior pair separated by a distance approximately one-half to one-third as great as that between setae of middle pair. Maxillary palpus with two segments, basal segment without accessory process, with one very short lateral seta, apical segment without lateral seta, apical segment longer than wide. Mala with five ventral and seven or eight dorsal setae.

Pronotum with ten setae. Thoracic spiracle bicameral, strongly transverse, twice or more as long as wide, paired air-tubes dorsal, very regularly annulated and together as wide as peritreme. Prodorsum of meso- and metathorax with one short seta. Postdorsum of meso- and metathorax with four setae, setae 1 and 2 short, subequal, 3 and 4 moderately long, subequal. Alar area with one short seta. Spiracular area with a short seta. Epipleurum with a seta. Pleurum of prothorax with two setae, of meso- and metathorax with a seta. Pedal area with seven setae, one moderately long, the remainder shorter and subequal to very short sternal seta. Sternal setae subequal to eusternal setae.

Abdomen with eight pairs of spiracles similar to those of prothorax, eighth abdominal spiracles closer to each other on dorsum, their distance about three to four times the length of total spiracle. Typical abdominal segments with three dorsal folds. Prodorsum with one short seta. Postdorsum of first to seventh segments with five setae, setae 1, 2 and 4 short, subequal, 3 and 5 moderately long, subequal, eight postdorsum with two setae, 1 short, 2 moderately long. Spiracular area with two setae, seta 1 very short, seta 2 short. Epipleurum with two setae, one short, the other slightly longer. Pleurum with two setae, one short, the other slightly longer. Pedal area with one short seta. Eusternum with two very short setae. Sternellum present. Anus terminal, with four lobes, lateral lobes large.

This genus may be characterized by the slender spiracle, and hair-like dense asperities between the labral rods.

Key to species examined

1. Mandible entire at apex. Clypeus angulate on each side at base 2

-. Mandible bidentate at apex. Clypeus not angulate at sides at base

2. Air-tubes of spiracles more than twice as long as peritreme ..... Dyscerus exsculptus -. Air-tubes of spiracles about 1.5 times as long as peritreme ....Dyscerus shikokuensis

3. Postmental seta 1 a little narrowly separated than 2. Air-tubes of spiracles almost as long as peritreme Dyscerus orientalis

-. Postmental seta 1 separated by one-third the distance between 2. Air-tubes of spiracles about 1.5 times as long as peritreme Dyscerus perforatus

Species and materials examined.

Dyscerus exsculptus (Roelofs). Yabemachi, Kumamoto Pref., 19.iii.1979, from treetrunk of chestnut. 
Dyscerus shikokuensis (Kôno). Aomori Pref., 12. vi. 1973, from three-trunk of apple tree.

Dyscerus perforatus (Roelofs). Shodoshima I., from tree-trunk of olive.

Dyscerus orientalis (Motschulsky). Tsu City, Mie Pref., 18. v. 1984, from tree-trunk of Illicium religinosum.

\section{Niphades variegatus Roelofs}

(Fig. 13)

Niphades variegatus: Hayashi, 1959, Ill. Ins. Larv. Jap., : 530. fig. 1000.

Body nearly cylindrical, moderately narrow, skin with minute asperities.

Head free, depressed, yellowish brown, with a short pale longitudinal streak on each side of epicranial suture, about as long as wide. Anterior ocellus present. Antenna with a conical segment and several minute setae. Catapophyses in same plane as frons. Hypopharyngeal bracon readily discernible. Frontal suture distinguishable throughout its length. Endocarina distinct, approximately one-half as long as frons. Frons strongly transverse, with five pairs of setae, setae 1, 2 and 3 short to moderately long, subequal, and 5 long, subequal. Dorsal epicranial setae 1, 3 and 5 long, subequal, 2 moderately long, 4 short. Lateral epicranial seta 1 moderately long, 2 long. Ventral epicranial setae short to moderately long, subequal. Four minute posterior epicranial setae present. Clypeus with angular sides and straight anterior edge. Clypeal seta 1 short to moderately long, nearly twice as long as 2 . Anterior margin of labrum trilobed, posterior margin strongly produced into clypeal zone. Labral setae 1 and 2 short to moderately long, nearly twice as long as 3. Median and paired lateral sensilla present on labrum. Labral rods moderately elongate, stout, subparallel. Epipharynx without asperities, with three anterolateral setae, six anteromedian setae and four median spines. Epipharyngeal sensory pores in two clusters, three in each cluster, between the anterior and posterior pairs of median spines. Mandible with two apical teeth. Mandibular seta 1 short, slightly longer than and directly behind 2. Labial palpus with two segments, basal and apical segment longer than wide. Premental sclerite complete as an elongate posteriorly acute triangle. Postmentum with three pairs of setae, seta 1 separated by a distance approximately one- half as great as that between seta 2. Maxillary palpus with two segments, basal segment without accessory process, with one very short seta, apical segment without lateral seta. Mala with five ventral and seven dorsal setae.

Pronotum with nine setae. Thoracic spiracle strongly transverse, twice or more as long as wide, paired air-tubes dorsal, very regularly annulated and together as wide as peritreme. Prodorsum of meso- and methathorax with one short seta. Postdorsum of meso- and metathorax with four setae, setae 1 and 2 short, subequal, 3 and 4 moderately long, subequal. Alar area with one short seta. Spiracular area with one minute and one moderately long seta. Epipleurum with one moderately long seta. Pleurum of prothorax with two setae, of meso- and metathorax with one seta. Pedal area with seven setae, one moderately long, the remainder shorter and subequal to short sternal seta. Sternal setae subequal to eusternal setae.

Abdomen with eight pairs of spiracles. Spiracles all lateral, same as those of 


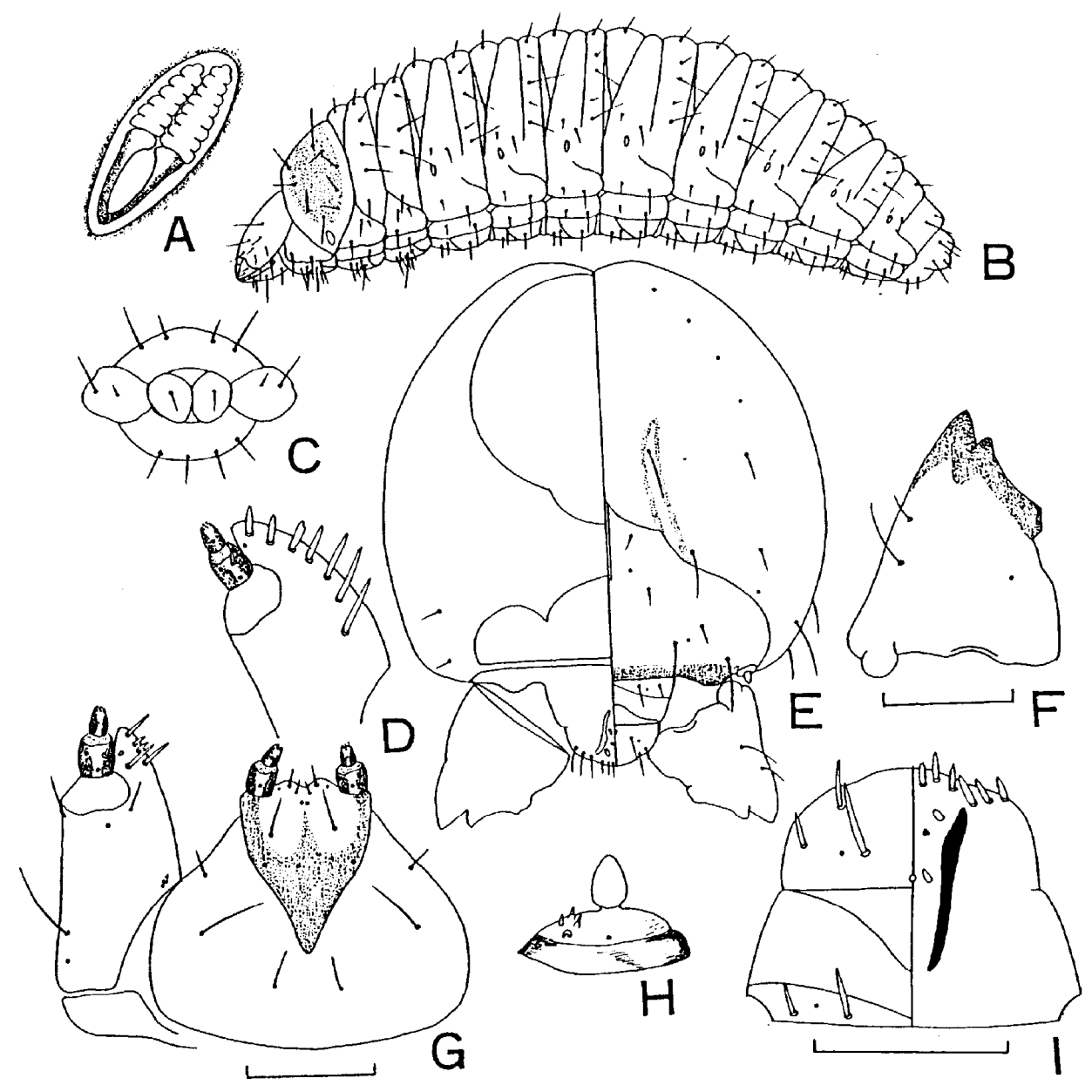

Fig. 13. Niphadesvariegatus Roelofs

A: Spiracle. B: Mature larva. C: Anus. D: Maxilla, dorsal. E: Head. F: Mandible.

G: Maxilla and labium. H: Antenna. I: Labrum and epipharynx. Scale: $0.5 \mathrm{~mm}$.

prothorax, air-tubes of anterior segments directed dorso-posteriorly and those of posterior segments directed posteriorly, eighth abdominal spiracles only more narrowly separated than those on seventh. Typical abdominal segments with three dorsal folds. Prodorsum with one short seta. First to seventh postdorsum of abdomen with five setae, setae 1, 2 and 4 short, subequal, 3 and 5 moderately long, subequal. Typical abdominal segment 8th with two setae, 1 short, 2 moderately long. Spiracular area with two setae, seta 1 very short, seta 2 short. Epipleurum with two setae, one short, the other slightly longer. Pleurum with two setae, one short, the other slightly longer. Pedal area with one 
short seta. Eusternum with two very short setae. Sternellum present. Anus terminal, with four lobes, lateral lobes large.

Width of head $0.23 \mathrm{~mm}$.

Materials examined. Mt.Tatsudayama, Kumamoto City, 6.v. 1969, under bark of dead pine trees. 